\title{
Spiritual Pathways to Healing and Recovery: An Intensive Single-N Study of an Eating Disorder Patient
}

\author{
Kawika Allen \\ Brigham Young University, gekawika_allen@byu.edu \\ Troy Lea \\ Brigham Young University \\ P. Scott Richards \\ Brigham Young University, scott_richards@byu.edu \\ Peter W. Sanders \\ Brigham Young University, peter_sanders@byu.edu \\ Jason A. McBride

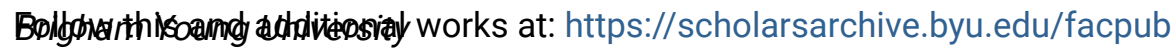 \\ Part of the Mental and Social Health Commons
}

\section{Original Publication Citation}

Lea, T., Richards, P. S., *Sanders, P. W., *McBride, J. A., \& Allen, G. E. K. (2015). Spiritual pathways to healing and recovery: An intensive single-N study of an eating disorder patient. Spirituality in Clinical Practice, 2(3), 191.

\section{BYU ScholarsArchive Citation}

Allen, Kawika; Lea, Troy; Richards, P. Scott; Sanders, Peter W.; and McBride, Jason A., "Spiritual Pathways to Healing and Recovery: An Intensive Single-N Study of an Eating Disorder Patient" (2015). Faculty Publications. 3175.

https://scholarsarchive.byu.edu/facpub/3175

This Peer-Reviewed Article is brought to you for free and open access by BYU ScholarsArchive. It has been accepted for inclusion in Faculty Publications by an authorized administrator of BYU ScholarsArchive. For more information, please contact ellen_amatangelo@byu.edu. 


\title{
Spiritual Pathways to Healing and Recovery: An Intensive Single- $N$ Study of an Eating Disorder Patient
}

\author{
Troy Lea, P. Scott Richards, Peter W. Sanders, \\ Jason A. McBride, and G. E. Kawika Allen \\ Brigham Young University
}

\begin{abstract}
This article presents an in-depth single case study of 8 sessions of spiritually integrated psychotherapy with a 20-year-old woman recovering from an Eating Disorder. The inclusion and utility of session-to-session outcome data as well as systematic follow up data in conjunction with in-depth qualitative interviews are shown. Dr. $\mathrm{H}$ and client's perspectives are highlighted over the course of treatment. Clinical areas of focus were extracted from the the qualitative interviews and the therapeutic process is described. Single-case study statistical analyses were conducted to highlight clinical gains and maintenance.
\end{abstract}

Keywords: case study, effectiveness, interventions, psychotherapy, spirituality

It is now widely recognized in the medical and psychological professions that faith and spirituality are often positively associated with physical and mental health (Koenig, McCullough, \& Larson, 2001). Despite this, professionals in the eating disorders field have largely neglected the role of faith and spirituality in treatment and recovery (Richards, Weingarten-Litman, Berrett, \& Susov, 2013). If eating disorder treatment programs were more successful at helping women heal and recover from their eating disorders, perhaps there would be no reason to investigate the potential role of spirituality in facilitating recovery. However, success rates of most contemporary eating disorder treatment programs have been relatively low (Richards et al., 2000; Steinhausen \& Weber, 2009). There is clearly a need for the development and evaluation of new interven-

Troy Lea, P. Scott Richards, Peter W. Sanders, Jason A. McBride, and G. E. Kawika Allen, Department of Counseling Psychology, Brigham Young University.

This research was supported by grants from the John Templeton Foundation and from the David O. McKay School of Education at Brigham Young University. We also thank Blake Hansen who assisted with the quantitative data analysis.

Correspondence concerning this article should be addressed to P. Scott Richards, Department of Counseling Psychology, 340 MCKB, Brigham Young University, Provo, UT 84602. E-mail: scott_richards@byu.edu tions that show promise for helping more women recover from eating disorders.

There are both theoretical and empirical reasons to hypothesize that faith and spirituality may contribute to better treatment outcomes among women with eating disorders. Some authors have theorized that eating disorder patients struggle with several core issues that are spiritual in nature, and that spiritual interventions are the most effective way to address them (Richards et al., 2013). With regard to the empirical findings: (a) Survey and interview studies of recovered eating disorder patients have found that sizable percentages of such women report that faith and spirituality were very important in their recovery (e.g., Marsden, Karagianni, \& Morgan, 2007; Rorty, Yager, \& Rossotto, 1993); (b) A quantitative correlational study of eating disorder inpatients revealed that improvements in spiritual well-being during treatment were associated with reductions in eating disorder symptoms and psychological disturbance (Smith, Hardman, Richards, \& Fischer, 2003); and (c) A phase one clinical trial revealed that women in an eating disorder inpatient treatment program who participated in a spirituality group intervention enjoyed better treatment outcomes than patients in other treatment conditions (Richards, Berrett, Hardman, \& Eggett, 2006). 
Despite these promising empirical findings, the evidence-base supporting the use of spiritual treatment approaches for eating disorders remains provisional (Richards et al., 2013). There is a need for additional treatment outcome studies to further document the effectiveness and efficacy of various types of spiritual approaches in the eating disorders field. We also do not have much insight yet into how clinicians can effectively integrate spiritual approaches into eating disorder treatment, or why spirituality may facilitate recovery.

The APA Task Force's report on evidencebased practice in psychology (American Psychological Association, Presidential Task Force on Evidence-Based Practice, 2006) affirms that multiple types of research designs can contribute to evidence-based practice, including randomized controlled trials, practice-based designs, qualitative research, individual case studies, systematic case studies, single- $N$ studies, and process-outcome studies. In speaking of case reports, single- $N$ studies, and qualitative research, the Task Force's report affirmed the value of such designs for clinical innovation, hypotheses generation, giving insight into the lived experience of clients, demonstrating the ecological validity of interventions, and establishing causal relationships in the context of individual clients (American Psychological Association, Presidential Task Force on EvidenceBased Practice, 2006).

In light of this, we decided that using an intensive single- $N$ case design with both quantitative and qualitative methodologies would be helpful for exploring the spiritual processes and mechanisms of change that facilitate eating disorder treatment and recovery. The overall purpose of our study was to conduct an in-depth exploration of a theistic, spiritually oriented treatment approach for an eating disorder client in an outpatient treatment setting. We investigated the following research questions:

1. What spiritual perspectives and interventions were used in the treatment of the client and how did they interplay with traditional therapy approaches?

2. What was the overall experienced process of the client during her spiritually oriented treatment approach?
3. What were the therapist's treatment goals and how were they received and incorporated (or not) into the client's life?

4. Based on the quantitative and qualitative evidence collected during the study and during the posttreatment follow-up, what improvements did the client experience?

\section{Method}

\section{Participants}

Psychotherapist. The psychotherapist in this study, hereafter referred to as "Dr. H," was a licensed psychologist with 30 years experience as a full time practitioner. Dr. $\mathrm{H}$ reported that he integrates theistic, spiritual perspectives with cognitive-behavioral therapy and family systems approaches. During his career he worked at a family practice clinic and then cofounded a nationally renowned inpatient eating disorder clinic. He currently works as a psychologist in the counseling center at BYUIdaho (BYU-I).

Client. The client participant, hereafter referred to as Stephanie (a pseudonym), was one of more than 300 clients who participated in an outcome study conducted at the BYU-I counseling center. At the time of treatment, Stephanie was 20 years old, single, and without children. She had previously been in counseling for several years at an eating disorder treatment center and had been referred to Dr. $\mathrm{H}$ from this facility. Stephanie reported having developed her eating disorder when she was 16 . She reported primarily restricting, but also occasional episodes of binging and purging. Stephanie also reported a history of excessive exercise.

At the beginning of treatment, Stephanie started the antidepressant medication Zoloft. Stephanie's diagnoses were 296.32 major depressive disorder, recurrent, moderate, 307.50 unspecified eating disorder, 300.00 unspecified anxiety disorder, and 301.9 personality disorder NOS. Stephanie was seen in treatment at the counseling center a total of eight sessions over a 3-month period.

Stephanie was a member of the Church of Jesus Christ of Latter-day Saints. However, she reported only being partially involved in her religion the past couple years. She said she had "never stopped attending" her church services, 
but struggled to participate or feel a sense of belonging.

\section{Procedures}

This single- $N$ case study occurred in the context of a larger study of the processes and outcomes of spiritually oriented psychotherapy at the BYU-I counseling center from March 11, 2013 to February 28, 2014 (Sanders et al., 2015). Because the procedures are described in the Sanders et al. study, they will not be described in detail here. Briefly, Stephanie completed a Spiritual Intake Questionnaire, Theistic Spiritual Outcome Survey (TSOS; Richards et al., 2005), and the Clinically Adaptive Client Outcome Measure (CA-COM; Richards, Sanders, McBride, \& Lea, 2014) before each of her therapy sessions. One-year after the termination of treatment, Stephanie completed the CA-COM again and the Eating Attitudes Test (EAT; Garner, Olmsted, Bohr, \& Garfinkel, 1982). At the conclusion of each therapy session, Dr. H completed the Clinically Adaptive Therapist Session Checklist (CA-TSC; Richards et al., 2014), which he used to summarize what topics were discussed during each session and what spiritual interventions he used. Dr. $\mathrm{H}$ also received summaries of the outcome assessment results for Stephanie each week to assist in treatment planning.

\section{Quantitative Data Analysis}

We first calculated the percentage of change attributed to psychotherapy using the Tau-U effect size estimate (Parker, Vannest, Davis, \& Sauber, 2011). We used an AB model to compare the first two CA-COM surveys with the following six sessions. The Tau-U estimate is a nonparametric statistical analysis that measures nonoverlap between two phases, usually a baseline and intervention phase, in single- $N$ designs. We used Stephanie's first two responses to the CA-COM (intake and postintake testing administrations) as the baseline because Dr. $\mathrm{H}$ did not report using any spiritual interventions in the first session. Second, we conducted a two phase-effect analysis using Simulation Modeling Analysis Software (SMA; Borckardt, Nash, Balliet, Galloway, \& Madan, 2013) to test whether Stephanie reported a significant change on any of the eight therapeutic dimensions.

\section{Qualitative Interviews and Data Analysis}

In addition to the quantitative outcome data, two semistructured interviews were conducted with Dr. $\mathrm{H}$ two and four months after the termination of treatment. Additional qualitative analyses were conducted on the four written explanations provided by Dr. $\mathrm{H}$ about his treatment approach. Ten months after Stephanie terminated treatment, the primary researcher (first author) conducted a semistructured qualitative interview with her.

\section{Results}

\section{Quantitative Findings}

Table 1 summarizes data from the CA-TSC and shows what types of spiritual interventions Dr. H used during each session in his work with Stephanie. During the first session, Dr. H conducted a diagnostic and assessment interview, which included a religious and spiritual assessment. In subsequent sessions, the most frequently used spiritual interventions Dr. H used included praying silently, talking with Stephanie about listening to her heart, teaching spiritual concepts, and encouraging Stephanie to accept God's love.

Figure 1 presents Stephanie's score on each of the CA-COM dimensions during the eight sessions of treatment and at the 10-month follow-up. The graphs reveal that Stephanie's level of distress decreased over the course of therapy in all the dimensions, except that of relationship concerns which saw a slight climb in the 8th and final session. This may be attributable to the relationship strain of termination. The CA-TSC data (arrows) show that Dr. $\mathrm{H}$ focused in early sessions on Stephanie's distressing thoughts, self-defeating behavior, spiritual concerns, and distressing emotions, but shifted focus later in treatment to relationship concerns and physical health concerns. The CA-TSC arrows also reveal that Stephanie's level of distress about different concerns tended to decline after these issues were addressed during therapy sessions.

Use of the aggregated eight dimensions of the CA-COM yielded a Tau- $U$ estimate of -0.410 (0.488), which is statistically significant at a $p=$ .017 , and indicates a $41 \%$ improvement of change across the eight dimensions from baseline to intervention. The Simulation Modeling Analysis 
Table 1

Spiritual Interventions Dr. H Used Each Treatment Session

\begin{tabular}{|c|c|c|c|c|c|c|c|c|}
\hline \multirow[b]{2}{*}{ Spiritual intervention } & \multicolumn{8}{|c|}{ Session } \\
\hline & 1 & 2 & 3 & 4 & 5 & 6 & 7 & 8 \\
\hline Charitable service & & & & & $\checkmark$ & & & \\
\hline Forgiveness & & $\checkmark$ & & & $\checkmark$ & & & \\
\hline Discussed scriptures & & & $\checkmark$ & & & & & \\
\hline Referral for blessing & & & $\checkmark$ & & & & & \\
\hline Spiritual journal writing & & $\checkmark$ & & & & & & \\
\hline Spiritual relaxation or imagery & & & & & & & $\checkmark$ & \\
\hline Spiritual self-disclosure & & & & & & $\checkmark$ & & \\
\hline Teaching spiritual concepts & & $\checkmark$ & & $\checkmark$ & & $\checkmark$ & $\checkmark$ & $\checkmark$ \\
\hline Prayer-silent therapist prayer & & $\checkmark$ & $\checkmark$ & $\checkmark$ & $\checkmark$ & $\checkmark$ & $\checkmark$ & $\checkmark$ \\
\hline Use of religious community & & & & & & $\checkmark$ & $\checkmark$ & \\
\hline Listening to the heart & & $\checkmark$ & $\checkmark$ & $\checkmark$ & $\checkmark$ & $\checkmark$ & $\checkmark$ & \\
\hline Trusting God & & & & & & $\checkmark$ & & \\
\hline Accept God's love & & $\checkmark$ & $\checkmark$ & & $\checkmark$ & & & $\checkmark$ \\
\hline Client private prayer & & & & & & & & $\checkmark$ \\
\hline Encouraging personal prayer & & $\checkmark$ & $\checkmark$ & $\checkmark$ & & & & \\
\hline Diagnostic/assessment interview & $\checkmark$ & & & & & & & \\
\hline
\end{tabular}

(Borckardt et al., 2013) indicated that Stephanie's changes on the Distressing Behaviors (Baseline, $M=3.5$; Intervention, $M=2.43 ; r=+0.78, p=$ .021 ), Distressing Emotions (Baseline, $M=4.5$; Intervention, $M=3.0 ; r=+0.88, p=.025)$, Distressing Thoughts (Baseline, $M=4.0$; Intervention, $M=3.14 ; r=+0.87, p=.025)$, and Physical Health (Baseline, $M=4.5$; Intervention,
$M=3.57 ; r=+0.83, p=.038)$ dimensions were statistically significant. Additionally, Stephanie completed an EAT survey a year after terminating therapy. Her response of 14 was well below the normal range cutoff of 30 , indicating healthy eating attitudes. Thus, the quantitative findings provide evidence that Stephanie achieved significant improvements over the course of her treatment

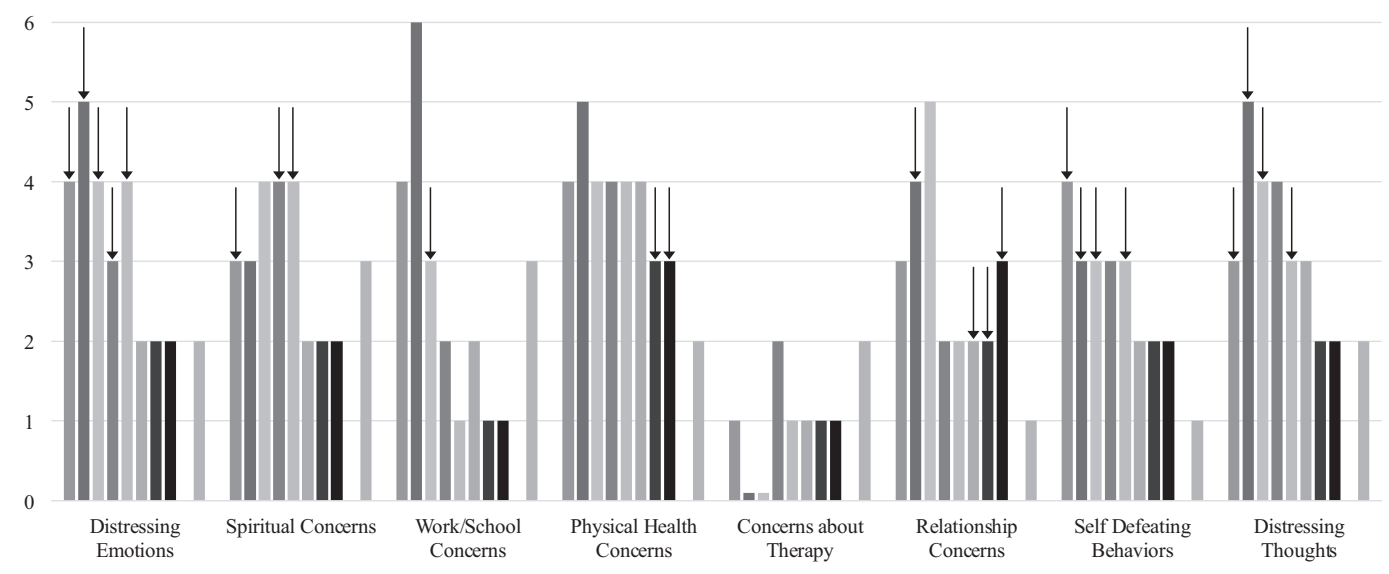

Figure 1. Stephanie's improvement on the 8 dimensions of the CA-COM. $\downarrow=$ Indicates therapist marked this as a clinical focus on the TSC during that session. Response scale for $\mathrm{Y}$ axis is $0=$ no response $; 1=$ never $; 2=$ rarely; $3=$ sometimes $; 4=$ frequently; $5=$ almost always; 6 = always. 
and that she maintained them nearly a year after treatment.

\section{Qualitative Findings}

The therapist's story. Dr. H reported early in treatment that he spent time providing some psycho-education on ways he believe eating disorders work. Dr. H explained that Stephanie and he focused much attention on the "underlying emotions and contributors to the eating disorder." He also took time to discuss dietary and nutritional aspects of treatment due to the fact that the BYU-I counseling center did not have dietician services. Dr. $\mathrm{H}$ also described helping Stephanie correct some unhealthy behavior cycles:

\begin{abstract}
When I started seeing her . . . , at that point, [she] was failing all of her classes, was not attending class, was not working very much on her homework ... She also had a part-time job here that once she was there she did pretty well, but it was hard to get into it. We would talk about structures and strategies to ... get her to class, to work on homework ... we shortened study time so she could stay focused for longer.
\end{abstract}

In addition, Dr. $\mathrm{H}$ reported that his treatment with Stephanie focused on five key issues: addressing cognitive distortions, engaging avoidance patterns, renewing identity development, creating healthy behavior patterns, and addressing spiritual misconceptions. With all of these issues, Dr. H interwove spiritual concepts specific to Stephanie's religion.

Dr. H reported that he would engage Stephanie's depression with "a cognitive behavioral model." He explained that he would help her "challenge some of her negative thinking about herself, about life, helping her reframe things that were going on in her life so she didn't end up with the worst meaning always." He went on to explain that he would use a concept of selfkindness. He explained to Stephanie that selfkindness is choosing to be kind to one's self in the moment even if she did not feel fully accepting of herself, whereas self-acceptance is more a felt sense of total acceptance.

Dr. H explained that in therapy Stephanie and he would examine Stephanie's avoidance patterns. He stated that she would often "get shut down and depressed" with minor set backs or criticisms. He stated that she would attempt to be in control through "avoiding things." Dr. H introduced a concept he terms the "four levels of honesty," which is described in detail in
Hardman, Berrett, Richards, and Black (2015). Briefly, Dr. H explained that he talked to Stephanie "throughout our working together on the four levels of honesty-about learning to be honest without self-judgment, self-blame, and how to start being more honest through self-kindness and choice-that was very helpful to her."

Dr. $\mathrm{H}$ also focused Stephanie on her own identity and how she could renew her sense of self. He introduced two identity and religious concepts for Stephanie. The first is that her current identity development was so dependent on externalized information that there was no clear distinction between "who I am" and "what I do." Stephanie clarified that in reality it is not "what I do" that she was struggling with, but actually "all the emphasis is on what [she] doesn't do well."

Dr. H introduced the "Atonement" and God's love, two key religious principles consistent with Stephanie's religious background, as alternatives to Stephanie's identity formation. The atonement, as Dr. $\mathrm{H}$ described it, involves the sacrifice of Jesus Christ for the salvation of humanity. Dr. H explained, "God knows who you are and he also knows what you do. But we need to leave room between 'what I do' and 'who I am,' otherwise you're left to your own devices." In addition to these in session discussions, Dr. H recommended small sections of The Continuous Atonement (Wilcox, 2009) and small sections of Weakness Is Not Sin (Ulrich, 2009), which highlighted specific points important to clarifying Latter-day Saint understandings of Jesus Christ's atonement.

Dr. $\mathrm{H}$ also shared his perception with Stephanie that she had only been focusing on one aspect of her identity, namely the eating disorder. Dr. $\mathrm{H}$ helped her to understand the complexity of her identity - that she is much more than just an eating disorder.

Dr. $\mathrm{H}$ also introduced the concept of outcome versus process living. He shared his perception with Stephanie that her life was completely focused on the "do" aspects of life. He explained that for Stephanie to recover, she needed to have a balance of both outcome and process goals. She needed to value "her experience, her learning, her understanding, her heart, her intuition, her relationship, and all that's internal, or that's inside of her."

Dr. H also discussed Stephanie's relationship priorities, pointing out to her that she had placed 
relationship with others above her relationship with herself and with God. He explained: "We had to change the order. We had to go God first, self second, others third ... so that all of the focus wasn't on other people."

Dr. $\mathrm{H}$ explained that he would frequently "frame things in a spiritual context" in his work with Stephanie. His work was guided in part by a clinical framework called "six spiritual pathways to recovery from an eating disorder," which is described in detail in Berrett, Hardman, and Richards (2010).

The first spiritual pathway is listening to and following the heart. Dr. H explained that teaching patients to listen to their heart helps them "remember intuitively and deeply the important truths about who they really are. It helps them remember what matters most in their lives. The heart helps them remember who truly loves them." In addition to reawaking clients' sense of identity and values, Dr. $\mathrm{H}$ believes that listening to the heart is also a powerful and universal way of engaging a client's spirituality. He stated: "I believe that by listening to their hearts again [the patients] will remember that they are not alone in this world, and that they are surrounded by seen and unseen influences of good."

With Stephanie, Dr. H would ask her to listen her heart and highlight the spiritual impressions that came into her heart and bring them into session so that they could talk about them and reflect on how they could help her in the change process.

The second spiritual pathway is learning a language of spirituality. In working this pathway, Dr. H sought to understand and find common ground with Stephanie's spiritual language and to use her language in sessions. For example, Stephanie understood the concepts of light and dark from a spiritual perspective and so Dr. $\mathrm{H}$ used this language to discuss the variety of possible choices available to Stephanie:

If Stephanie's choices were in light, she felt edified, uplifted, she felt peace, it felt like there were more good things available to her, it enlarged her view of things. If she chose out of darkness, then it restricted things and limited them. She felt more was missing and it felt more like that there were less good things available. I tried to teach her that a choice was not good or bad, right or wrong. It's simply to tune into her heart and ask: Is this a heart choice? And if so, it's going to create light or more room or abundance. If it's an eating disorder choice, it's going to restrict me, make me feel bad, limit me.

Dr. $\mathrm{H}$ also worked with Stephanie on the third pathway, which is mindfulness and spiritual mindedness. Dr. H encouraged Stephanie to listen to her heart to help ground her in the present moment. He explained that the mind can be in past, present, and future, but the body and heart are always in the present. He stated:

Most of the time [Stephanie] lived her life in her mind.
It was in the past, or it was in the future, but she was
not present ... and if we can get her mind and her body
and her heart in the same spot, she'll feel connected to
herself, she'll feel connected to God, she'll feel con-
nected to others. So what I used to say to her a lot is,
be yourself, show up, be connected, be present, and
later you can think about it if you want to.

The fourth spiritual pathway Dr. H used was principled living. In this pathway a client is able to courageously endeavor to align their behaviors with their deeply felt religious convictions. Dr. $\mathrm{H}$ explained how the balance between process versus outcome living also relates to spirituality: "Spiritual outcomes are obedience and keeping the commandments. And spiritual process is a change of heart and being new creatures in God." He helped Stephanie see how she had focused her religious participation primarily on the outcome aspects of religiosity.

The fifth pathway Dr. H utilized was giving and receiving good gifts of love. In this pathway, Dr. H asked Stephanie go out and "look for God's love, look for love in other people, look for love, look for God out there in her day to day life because she had a terrible case of eating disorder tunnel vision."

Holding up a therapeutic mirror that reflects spiritual identity is the sixth and final pathway. In this pathway, Dr. $\mathrm{H}$ used positive statements and praise to help Stephanie see new and positive aspects of herself. He explained that with Stephanie he often "held up the mirror to her so she could see God's light and love in herself and how she was being with other people."

In addition to these six spiritual pathways, Dr. $\mathrm{H}$ also shared his own openness to spiritual guidance over the course of therapy. He stated:

I pray before every session. I do. I know I cannot do this [alone]. We all need God's help. But when I have an impression come to my heart or my mind through the spirit, I always say it. Even if we're doing something different I'll say it. I'll act on it. And I've found that it's 
almost always well received. And it's often times just what they needed.

Dr. $\mathrm{H}$ shared how he received spiritual guidance during one experiential intervention with Stephanie. Dr. H began working with Stephanie's self-contempt in the beginning of one particular session after she reported having "a terrible body image." Dr. H explained that he began exploring Stephanie's thoughts and emotions in a very "CBT way," but received a spiritual impression to use a spiritual intervention. He asked Stephanie to "imagine how God viewed her body, not how she saw her body, but how God saw her body." Dr. H then placed a chair in front of Stephanie with her backpack in it and asked her to imagine the backpack was her body and to listen to her heart to get a sense of how God views her body. Dr. H explained the results of the exercise:

She had a powerful spiritual experience where she felt like she knew how God viewed her body. She got a sense of it, a spiritual sense of it . . . how God valued her body and that God saw her body as beautiful and acceptable and had a purpose and was important and had a role. ... And it was profound.

Dr. H went on to explain that after that experience Stephanie still struggled with her own feelings of self-contempt, "but that ... she said okay, I know what God's perspective is now and so I want to pursue that. And it gave her hope and it gave her a deeper sense of what her body really meant." Dr. H encouraged Stephanie to seek, through prayer, continued confirmation about how God views her body, as well as ask for help aligning her own beliefs about her body with her felt sense of God's beliefs.

Commenting on his termination of treatment with Stephanie, Dr. H said:

Stephanie still had work to do. ... But ... what made it different for her now is that she had hope. She knew she could recover. She knew God would help her recover. She knew that her view of herself had changed because she had felt God's kindness.

Stephanie's story. The follow-up interview with Stephanie yielded insights into two general issues: (a) how Stephanie viewed her eating disorder and (b) what therapeutic solutions Stephanie felt helped in recovery.

Stephanie explained that while growing up in a Latter-day Saint community, she felt "So much pressure, to be perfect." She said many of the women in her community struggle with the "ideal image of what you need to be." She would often compare herself with her peers, who she thought all seemed to have better grades than her and more academic accomplishments. She recalled feeling, "If you don't have it all together, you're not good, you're not worth anything." The pressure continued during her experience at BYU-Idaho. She said her depression was partly attributable to that fact that "I end up failing because I expect too much of myself."

Stephanie explained the pressure and selfcriticism caused a lot of self-contempt. "I just didn't like myself, as a person, I didn't think I was good, I thought I was bad." She explained how the feelings of depression spiraled into her eating disorder:

I just felt bad about myself. I knew there was just this
thing that was like bringing me down, I was so de-
pressed, like I was always down and just even my
thoughts were bad you know? You let it control your
thoughts and then control your whole body and then
you do not know you're in a bad place, but sometimes
it's easier to just stay there than it is to improve.

Stephanie explained that the feelings of depression focused on her body:

\begin{abstract}
I had a huge problem with my body, but the bigger problem was I just didn't like myself . . . I'm not good at going to church all the time, and I have depression, and I have these spirals out of control, and I do not have that many friends and all these little things pile up and the I would take it out on my body. I would say the whole problem here is I'm not fit enough because if I was thinner, everything would be perfect.
\end{abstract}

This fixation on thinness became more and more set until Stephanie lost touch with who she was and what she wanted-all she had room for was her eating disorder. She said, "For a long time, I don't think I really knew who I was. I didn't like who I was ... I was always bad and I was always fixated on my body."

Stephanie believed there were several things that helped in her recovery. She explained that Dr. $\mathrm{H}$ and his approach were a big part of her healing. She also explained that she learned some important skills during treatment like the ability to resist comparing herself with others and to impart self-kindness. She also developed a deeper sense of her own identity, connection to what she loves, consistency with her medication, and ability to be present in a relationship despite having imperfections. 
Stephanie said that she stuck with therapy because of the relationship she was able to form with Dr. H. She described how "he always wanted to listen and hear everything I had to say." She said she trusted Dr. H because she always felt he wanted to listen to her. His interest in her opened "the floor up and so I would talk, and then he would kind of analyze it, and he would tell me what he thought, and yeah, I always believed when he said things spiritual because ... I just, I trust him." She also felt she could rely on Dr. H's clinical experience. Another reason she trusted Dr. $\mathrm{H}$ was because of the fact that he would "tell me things that were really hard to hear . . . like, 'you think you're fat' or 'you don't like your thighs.",

Stephanie also said that Dr. $\mathrm{H}$ had a supportive way of responding to her failures. She recalled several examples of occasions when Dr. $\mathrm{H}$ would say things like "it's okay, you did something, now let's just keep going, let's just keep working on it" or "okay, so you skipped class, that doesn't make you a bad person." She explained that these statements really helped her trust Dr. H and the therapy process. She explained that Dr. H would reinforce positive aspects about her like "you are a really loving person." She explained how important it was for her to feel "someone notices me, someone notices the good about me and someone was telling me the stuff that I needed to hear about myself." She believes that Dr. H was a great example of "someone who loves you, that you can trust, who will be honest with you and that will help you come into yourself."

Stephanie also recalled how important it was for her that Dr. H was "in tune with the spirit" and was able to "relate to all my beliefs." She explained that Dr. H's spiritual sensitivity also played out in a healing blessing she received from him toward the end of treatment. She said this experience greatly impacted her. She said the blessing continued to have special importance in her life after treatment and she would often recall it when she needed hope.

Stephanie talked at length about the impact Dr. H's integration of spirituality had on her own spirituality. She explained how he helped her (a) gain a sense of what God knows about her, (b) challenge incorrect feelings with correct spiritual principles, and (c) develop an increased measure of faith that God believed in her and would help her. She said: "I think the feeling that he gave me was just faith, and that [God] believed in me, and [God] believed that I could change. And that [God] was there to help me, and you know, pulling me up." Stephanie affirmed her belief that "God really does have a plan for me and I was meant to go through everything that I had to go through."

Stephanie explained that she had to "start taking care for myself. . . . I had to learn how to love myself, which is really hard." She said Dr. $\mathrm{H}$ helped her with this process by asking her to create a list of things she liked about herself that weren't physical. Dr. H asked her to read it to him in the subsequent session. She recalled, "that was really good for me, because you don't often . . . look in the mirror and tell yourself good things about yourself, you tell yourself bad things." Stephanie learned to tell herself that she was okay and

that there were things that I did like about myself. Like
even if I didn't like my legs, I could look in the mirror
and see there were twenty other things I liked about
myself that aren't . . . physical things . . . and then
learning to respect and take care of yourself.

Stephanie explained that she built on these small acts of self-kindness by "getting to class on time, and eating enough so that you're not starving so that you can focus more on your classes, so that you can do all these different things." She also began to take her medication regularly, something she had struggled with before her treatment due to the stigma about psychotropic medication. She came to realize that "when you're off your medication, that's not who you really are." She took her medications regularly and would "get to bed on time, take care of myself, eat enough food. When I do all that it just enables me to be who I really am."

During this process of taking control of her own self-care, Stephanie realized she was "learning how to love myself and accept myself for who I was and then, I just kind of . . . went to that place of being able to love myself, like I was so open to growth." Stephanie explained that this growth began to blossom into a renewed sense of identity. She proclaimed, "I'm finally to the point where I'm more okay with myself . . . this is who I am, and I like who I am."

Stephanie continued her process of discovery after leaving treatment. She started working with a dietician. She recalled that the 
dietician asked her to make a list of all the foods she liked. "I was like, oh my gosh, what kind of food do I even like? I didn't even know. I didn't even know what kind of food I liked because all it was this stuff I put down my throat and then throw up." She embarked on a food tasting quest to find her favorite foods. She described the experience as "empowering." She noted that she felt this journey of discovery was possible only because she had stopped "being obsessed over myself" and was able to "to like herself."

Another important step in Stephanie's recovery after treatment was opening up to her own values and passions. She explained that she started doing floral arrangements again after leaving treatment. She said she had done it before and had really enjoyed it, but she had given it up because her parents had told her she would "never make any money." As she reengaged in creating floral arrangements, she experienced greater fulfillment. She said, "I wasn't weighing myself every day, I wasn't like so concerned about stuff, I was who I was."

Lastly, Stephanie was able to explain how treatment had allowed her to engage in meaningful and sincere relationships. She explained that before treatment she felt she had to "figure it all out" before getting into a relationship. Stephanie describes the process of dating the man who is now her now husband:

I think something that was good for me was finding him, and it's so cheesy to say it, but, my other half, and him loving me so much that he was willing to stand by me while I go through all of this, while I figure out who I am, and I figure out what I like and become more confident in myself.

Stephanie said she feels one of the best things she has been able to accomplish since treatment is to be vulnerable and fully engaged in her relationship with her husband.

In summing up her feelings about treatment, Stephanie said,

It still wasn't good when I [finished treatment], but as I worked on it, I knew . . . this was the happiest I have ever been in my entire life. . . God really does have a plan for me and I was meant to go through everything that I had to go through, and that's when I knew, for real, that this was my purpose and God blesses me. You think that we go through all this hard stuff and it's not going get any better, but it does.

\section{Discussion}

The single- $N$ case study research design was an informative and rich methodology for the examination of Stephanie's treatment experience. It provided important insights into why and when spiritually oriented interventions were helpful in Stephanie's treatment. Stephanie's progress was impressive in light of the finding that only about $27 \%$ of bulimia patients report "bingeing and purging less than once per month" at posttreatment follow up (Richards et al., 2000) and only about $45 \%$ of patients diagnosed with bulimia recover (Steinhausen \& Weber, 2009). These statistics show that it is relatively infrequent for eating disorder patients to experience the amount of improvement Stephanie reported. Additionally remarkable was the long-lasting effect Stephanie's treatment had on her beliefs and life as evidenced in her and Dr. H's interviews.

This case study illustrates how a patient's religious community and religious interpretations can influence the development and retention of an eating disorder, a finding that is consistent with previous research that has shown religion may influence the development and etiology of eating disorders (Richards et al., 2013). Stephanie reported that her eating disorder originated in part, at least, out of struggles with perfectionistic tendencies consistent with religious beliefs about improvement toward perfection that she misunderstood and misapplied in her life. This is a common struggle within the Latter-day Saint community (Ulrich, Richards, Hansen, \& Bergin, 2014). Dr. H's denominationally adapted therapeutic approach allowed him to approach Stephanie's perfectionistic tendencies in a directive and educational manner. This helped Stephanie learn correct spiritual principles to challenge her negative and self-judgmental feelings.

Stephanie's case also provided clear insight into the therapeutic processes that were most effective in her healing. She acknowledged a powerful triad of attributes in the therapeutic alliance, specifically, Dr. H's openness to listen, patience with her in the process, and spiritual sensitivity and influences as primary contributors to her progress. Dr. H explained that he feels these attributes are related to his theistic framework of human nature and recovery, which have been written about in other sources 
(e.g., Richards, Hardman, \& Berrett, 2007). Stephanie explained that through these attributes she gained trust in Dr. H, which added even more to the power of her treatment experience. Dr. H's belief in the importance of seeking spiritual guidance to assist in the treatment process is shared by helping professionals from a diversity of religious and spiritual traditions (O’Grady \& Richards, 2010). For Stephanie, learning to listen to and trust the spiritual impressions of her heart was a powerful influence in her recovery (Berrett et al., 2010).

One of the drawbacks of single case methodology is limited generalizability and internal validity (Kazdin, 2011). As stated by Barkham, Stiles, Lambert, and Mellor-Clark (2010), "no single study can yield a definitive answer" (p. 22). However, this weakness can be addressed by continuing to repeat single case studies across varied contexts and conditions. Additionally, Sanders and colleagues (2015) performed data analysis on the entire sample of which Dr. $\mathrm{H}$ and Stephanie were a part, and found that the spiritually oriented therapy performed at the treatment site was effective. Thus, together these two research designs provided evidence about the effectiveness of theistic, spiritually oriented treatment. The present study gave more in-depth insight into the aggregate data that were presented in the Sanders et al. (2015) article by providing more details about how and why some of the spiritual interventions were used, how Stephanie experienced them, and why they were effective.

The synergy of these two studies provides an example of how researchers and practitioners can gain a greater understanding of the processes and outcomes of spiritually oriented psychotherapy through the collaboration advocated by Richards, Sanders, Lea, McBride, and Allen (2015). If researchers and practitioners from around the world engage in collaboration, it could allow for the analysis of the same data from multiple vantage points, allowing for the documentation of general trends, but also the exploration of the lived experience of individual practitioners and clients. Such research will not only help bridge the gap between research and practice, but also bridge the gap between mainstream secular psychotherapies and spiritually oriented approaches.

\section{References}

APA Presidential Task Force on Evidence-Based Practice. (2006). Evidence-based practice in psychology. American Psychologist, 61, 271-285. http://dx.doi.org/10.1037/0003-066X.61.4.271

Barkham, M., Stiles, W. B., Lambert, M. J., \& Mellor-Clark, J. (2010). Building a rigorous and relevant knowledge base for the psychological therapies. In M. Barkham, G. E. Hardy, \& J. Mellor-Clark (Eds.), Developing and delivering practice-based evidence: A guide for the psychological therapies (pp. 21-61). London, UK: Wiley-Blackwell. http://dx.doi.org/10.1002/ 9780470687994.ch2

Berrett, M. E., Hardman, R. K., \& Richards, P. S. (2010). The role of spirituality in eating disorder treatment and recovery. In M. Maine, D. Bunnell, \& B. McGilley (Eds.), Special issues in the treatment of eating disorders: Bridging the gaps (pp. 367-385). Maryland Heights, MO: Elsevier. http:// dx.doi.org/10.1016/B978-0-12-375668-8.10022-1

Borckardt, J. J., Nash, M. R., Balliet, W., Galloway, S., \& Madan, A. (2013). Time-series statistical analysis of single-case data. In G. J. Madden (Ed.), APA handbook of behavior analysis: Vol. 1. Methods and principles (pp. 251-266). Washington, DC: American Psychological Association.

Garner, D. M., Olmsted, M. P., Bohr, Y., \& Garfinkel, P. E. (1982). The eating attitudes test: Psychometric features and clinical correlates. Psychological Medicine, 12, 871-878. http://dx.doi.org/10 $.1017 /$ S0033291700049163

Hardman, R. K., Berrett, M. E., Richards, P. S., \& Black, S. (2015). Using experiential group therapy in the treatment of eating disorders. Eating Disorders: The Journal of Treatment \& Prevention, 23, 89-97. http://dx.doi.org/10.1080/10640266.2014 .940789

Kazdin, A. E. (2011). Single-case research designs: Methods for clinical and applied settings. New York, NY: Oxford University Press.

Koenig, H. G., McCullough, M. E., \& Larson, D. B. (2001). Handbook of religion and health. New York, NY: Oxford University Press. http://dx.doi .org/10.1093/acprof:oso/9780195118667.001 .0001

Marsden, P., Karagianni, E., \& Morgan, J. F. (2007). Spirituality and clinical care in eating disorders: A qualitative study. International Journal of Eating Disorders, 40, 7-12. http://dx.doi.org/10.1002/eat .20333

O'Grady, K. A., \& Richards, P. S. (2010). The role of inspiration in the helping professions. Psychology of Religion and Spirituality, 2, 57-66. http://dx.doi .org/10.1037/a0018551

Parker, R. I., Vannest, K. J., Davis, J. L., \& Sauber, S. B. (2011). Combining nonoverlap and trend for 
single-case research: Tau-U. Behavior Therapy, 42, 284-299. http://dx.doi.org/10.1016/j.beth .2010 .08 .006

Richards, P. S., Baldwin, B. M., Frost, H. A., Clark-sly, J. B., Berrett, M. E., \& Hardman, R. K. (2000). What works for treating eating disorders: A synthesis of 28 outcome reviews. Eating Disorders: The Journal of Treatment \& Prevention, 8, 189-206. http://dx.doi.org/10 .1080/10640260008251227

Richards, P. S., Berrett, M. E., Hardman, R. K., \& Eggett, D. L. (2006). Comparative efficacy of spirituality, cognitive, and emotional support groups for treating eating disorder inpatients. Eating Disorders: The Journal of Treatment \& Prevention, 14, 401-415. http://dx.doi.org/10 $.1080 / 10640260600952548$

Richards, P. S., Hardman, R. K., \& Berrett, M. E. (2007). Spiritual approaches in the treatment of women with eating disorders. Washington, DC: American Psychological Association. http://dx.doi .org/10.1037/11489-000

Richards, P. S., Sanders, P. W., McBride, J. A., \& Lea, T. (2014). Bridging the research-practice gap with a clinically adaptive internet-based outcome system. Paper presented at the annual convention of the American Psychological Association, August, 2014, Washington, DC.

Richards, P. S., Sanders, P. W., Lea, T., McBride, J. A., \& Allen, G. E. K. (2015). Bringing spiritually oriented psychotherapies into the health care mainstream: A call for worldwide collaboration. Spirituality in Clinical Practice, 2, 169-179. http://dx.doi.org/10.1037/scp0000082

Richards, P. S., Smith, T. B., Schowalter, M., Richard, M., Berrett, M. E., \& Hardman, R. K. (2005). Development and validation of the theistic spiritual outcome survey. Psychotherapy Research, 15, 457-469. http://dx.doi.org/10 .1080/10503300500091405

Richards, P. S., Weingarten-Litman, S., Berrett, M. E., \& Susov, S. (2013). Religion and spirituality in the etiology and treatment of eating disor- ders. In K. I. Pargament, A. Mahoney, \& E. Shafranske (Eds.), APA handbook of psychology, religion, and spirituality (Vol. II, pp. 319-333). Washington, DC: American Psychological Association.

Rorty, M., Yager, J., \& Rossotto, E. (1993). Why and how do women recover from bulimia nervosa? The subjective appraisals of forty women recovered for a year or more. International Journal of Eating Disorders, 14, 249-260. http://dx .doi.org/10.1002/1098-108X(199311)14:3< 249::AID-EAT2260140303>3.0.CO;2-O

Sanders, P. W., Richards, P. S., McBride, J. A., Lea, T., Hardman, R. K., \& Barnes, D. V. (2015). Processes and outcomes of theistic spiritually oriented psychotherapy: A practice-based evidence investigation. Spirituality in Clinical Practice, 2, 180-190. http://dx.doi.org/10.1037/scp0000083

Smith, F. T., Hardman, R. K., Richards, P. S., \& Fischer, L. (2003). Intrinsic religiousness and spiritual well-being as predictors of treatment outcome among women with eating disorders. Eating Disorders: The Journal of Treatment \& Prevention, 11, 15-26. http://dx.doi.org/10 .1080/10640260390167456-2199

Steinhausen, H. C., \& Weber, S. (2009). The outcome of bulimia nervosa: Findings from onequarter century of research. The American Journal of Psychiatry, 166, 1331-1341. http://dx.doi.org/ 10.1176/appi.ajp.2009.09040582

Ulrich, W. (2009). Weakness is not sin. Salt Lake City, UT: Deseret Book.

Ulrich, W. L., Richards, P. S., Hansen, K. L., \& Bergin, A. E. (2014). Psychotherapy with Latterday Saints. In P. S. Richards \& A. E. Bergin (Eds.), Handbook of psychotherapy and religious diversity (2nd ed., pp. 179-205). Washington, DC: American Psychological Association. http://dx.doi .org/10.1037/14371-008

Wilcox, B. (2009). The continuous atonement. Salt Lake City, UT: Deseret Book.

Received July 30, 2015 Accepted August 1, 2015 